\title{
Long term gastric $\mathrm{pH}$ monitoring for determining optimal dose of ranitidine for critically ill preterm and term neonates
}

\author{
Anna-Leena Kuusela
}

\begin{abstract}
Aim-To determine the optimal doses of ranitidine for both preterm and term infants.

Method-The effect of ranitidine treatment was measured from the long term intraluminal gastric $\mathrm{pH}$ in 16 preterm (gestational age under 37 weeks) and term infants treated in neonatal intensive care. The infants received three different bolus doses of ranitidine: $0.5 \mathrm{mg}, 1.0 \mathrm{mg}$, and 1.5 mg per kilogram of body weight to keep the intraluminal gastric pH above 4 on a 24 hour basis.

Results-Critically ill neonates, including very low birth weight infants, were capable of gastric acid formation, and ranitidine treatment increased the intraluminal gastric $\mathrm{pH}$. The effect of a single dose lasted longer in preterm than in term infants. The time needed for reaching the maximum gastric $\mathbf{p H}$ was significantly longer in preterm than in term infants. The ranitidine given correlated with the duration of increased gastric $\mathrm{pH}$ in a dose dependent manner both in preterm and term infants.

Conclusion-Preterm infants need significantly smaller doses of ranitidine than term neonates to keep their intraluminal gastric pH over 4 . The required optimal dose of ranitidine for preterm infants is $0.5 \mathrm{mg} / \mathrm{kg} / \mathrm{body}$ weight twice a day and that for term infants $1.5 \mathrm{mg} / \mathrm{kg}$ body weight three times a day.

(Arch Dis Child Fetal Neonatal Ed 1998;78:F151-F153)
\end{abstract}

Keywords: gastric $\mathrm{pH}$ monitoring; ranitidine

Critically ill patients run the risk of acute bleeding from stress induced gastric mucosal lesions. ${ }^{1}$ This includes neonates. ${ }^{2}$ The pathophysiology of the stress induced gastric lesions is not clear, but one of the influencing factors is low gastric acidity with hypoxaemia. ${ }^{3}$ Critically ill neonates are often hypoxaemic and therefore at severe risk of developing gastric lesions. Neonates and even preterm infants have good gastric acid production. ${ }^{5}$ Histamine 2 receptor blockers $\left(\mathrm{H}_{2}\right.$ blockers), such as cimetidine and ranitidine have most often been used to prevent gastric lesions in both adults and infants treated in intensive care..$^{6-9}$ The main effect of $\mathrm{H}_{2}$ blockers is to decrease the gastric acidity and to increase the gastric $\mathrm{pH}$ by inhibiting acid production. The serum concentration of ranitidine does not always correlate with gastric $\mathrm{pH}$ in neonates ${ }^{10} 11$ and so this measurement cannot be used to determine the optimal ranitidine dose.

We evaluated the effect of different doses of intravenous $\mathrm{H}_{2}$ blocker (ranitidine) on long term gastric $\mathrm{pH}$ in newborn infants treated in neonatal intensive care, to determine the optimal treatment dose of ranitidine for preterm and term infants.

\section{Methods}

Twenty two critically ill term and preterm neonates treated in the neonatal intensive care unit of Tampere University Hospital were studied. The neonates were included in the study if they were not being fed enterally and if they were prescribed ranitidine on clinical grounds soon after birth or within the first week of life (table 1). The exclusion criterion was gastric $\mathrm{pH}$ above 4 .

The long term gastric $\mathrm{pH}$ was monitored in all 22 critically ill neonates before starting ranitidine and if the gastric $\mathrm{pH}$ during the first three hours was constantly below 4, treatment was started. Six of the infants $(27 \%)$ were thus excluded from the study.

All neonates were mechanically ventilated, mostly for respiratory distress syndrome in the preterm infants and either surgery, meconium aspiration, or severe asphyxia after delivery in the term neonates. The gestational age ranged from 28 to 42 weeks (mean 33 weeks) and the mean birthweight was 2660 g (range 1000$4360 \mathrm{~g}$ ). Infants below the gestational age of 37 weeks were classified as preterm and the others as term. The clinical characteristics are shown in table 1 .

Ranitidine was thus given intravenously to 16 critically ill neonates in three different doses as boluses of : $0.5 \mathrm{mg} / \mathrm{kg}, 1.0 \mathrm{mg} / \mathrm{kg}$, and 1.5 $\mathrm{mg} / \mathrm{kg}$ body weight. The infants were randomly allocated to one of the three ranitidine groups, so that each child got only one fixed dose.

The continuous, long term 24 to 48 hour gastric $\mathrm{pH}$ monitoring was carried out using a Digitrapper Gold II (Synetics Medical, Stockholm, Sweden) $\mathrm{pH}$ monitor with one channel registration and a monocrystant antimony $\mathrm{pH}$ probe (91-0011 Monocrystant Antimony $\mathrm{pH}$ Catheter, Synetics Medical, Stockholm, Sweden). The $\mathrm{pH}$ measuring unit was calibrated using standard buffer solutions of $\mathrm{pH} 1$ and 7 before and after the assessment of the gastric $\mathrm{pH}$ of the patient. The data were collected every 4 seconds and analysed using the EsopHogram (Gastrosoft Inc., Irving, Texas, USA) analysis program. The probe was 
Table 1 Clinical characteristics of neonates treated with ranitidine

\begin{tabular}{lllll}
\hline $\begin{array}{l}\text { Gestational } \\
\text { weeks }\end{array}$ & Birthweight $(g)$ & Diagnosis & Reason for ranitidine treatment & $\begin{array}{l}\text { Dose of ranitidine } \\
\text { (mg/kg body weight) }\end{array}$ \\
\hline 30 & 1135 & Prematurity & Concomitant with corticosteroids & 0.5 \\
31 & 1750 & Prematurity & Melena & 0.5 \\
33 & 3000 & Omphalocele & Concomitant with indomethacin & 0.5 \\
39 & 3280 & Gastroschisis & Bloody nasogastric secretion & 0.5 \\
42 & 4360 & Asphyxia & Haematemesis & 0.5 \\
29 & 1000 & Prematurity & Concomitant with indomethacin & 1.0 \\
33 & 3000 & Duodenal atresia & Bloody nasogastric secretion & 1.0 \\
35 & 2440 & Prematurity & Concomitant with indomethacin & 1.0 \\
35 & 2470 & Gastroschisis & Haematemesis & 1.0 \\
39 & 2750 & Meconium aspiration & Gross blood in stools & 1.0 \\
40 & 3300 & Asphyxia & Haematemesis & 1.0 \\
28 & 1140 & Prematurity & Concomitant with corticosteroids & 1.5 \\
31 & 2000 & Prematurity & Concomitant with indomethacin & 1.5 \\
38 & 3330 & Asphyxia & Haematemesis & 1.5 \\
38 & 3300 & Eating disturbances & Haemorrhagic gastritis & 1.5 \\
39 & 4300 & Persistent pulmonary hypertension & Haematemesis & 1.5 \\
\hline
\end{tabular}

Table 2 Mean time (h) gastric pH stays over 4 in preterm and term infants after receiving three different doses of ranitidine

\begin{tabular}{|c|c|c|c|c|c|c|c|c|c|}
\hline \multirow{3}{*}{$\begin{array}{l}\text { Gestational } \\
\text { age (weeks) }\end{array}$} & \multicolumn{9}{|c|}{ Different doses of ranitidine treatment ( $\mathrm{mg} / \mathrm{kg}$ body weight) } \\
\hline & \multicolumn{3}{|l|}{0.5} & \multicolumn{3}{|l|}{1.0} & \multicolumn{3}{|l|}{1.5} \\
\hline & mean $(h)$ & $S D$ & $N$ & mean $(h)$ & $S D$ & $N$ & mean $(h)$ & $S D$ & $N$ \\
\hline $28-36$ & 10.17 & 1.3 & 3 & 12.75 & 2.2 & 4 & 20.75 & 1.1 & 2 \\
\hline $37-42$ & 4.75 & 1.1 & 2 & 6.50 & 1.4 & 2 & 7.67 & 0.8 & 3 \\
\hline
\end{tabular}

Two way analysis of variance: weeks: $\mathrm{p}<0.001$, dose: $\mathrm{p}<0.001$, interaction $\mathrm{p}=0.005$.
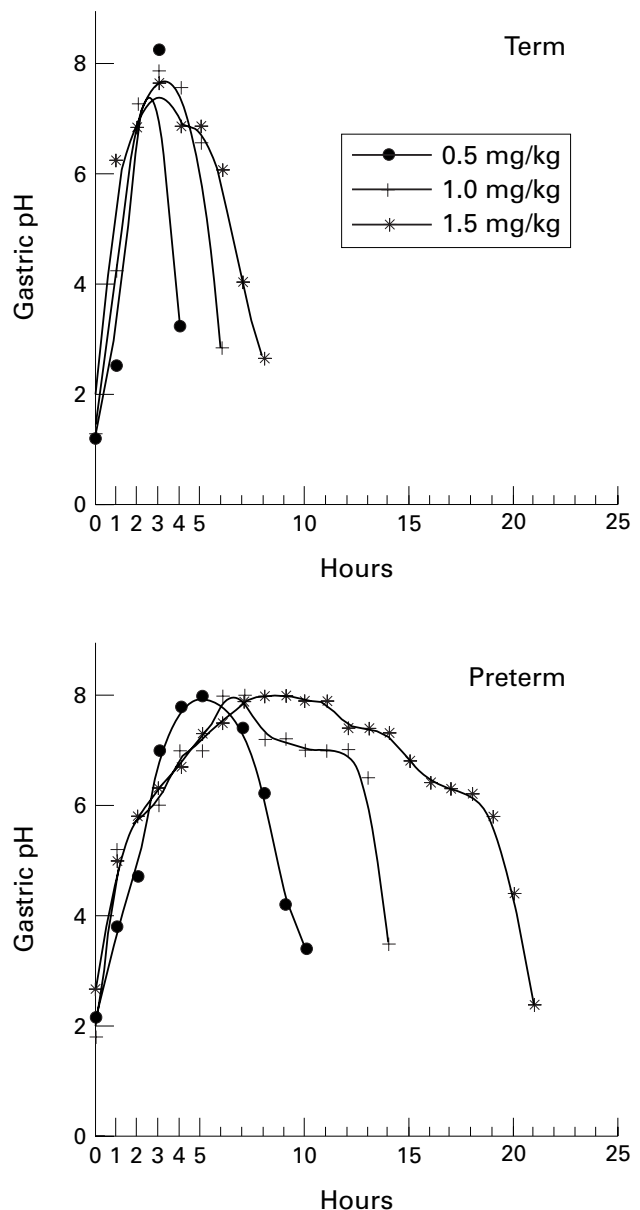

Figure 1 Gastric intraluminal pH curves of three term infants (top panel) and three preterm (gestational age less than 37 weeks) infants (bottom panel) after a bolus dose of ranitidine: $0.5 \mathrm{mg}, 1.0 \mathrm{mg}$, or $1.5 \mathrm{mg} / \mathrm{kg}$ body weight. inserted via the nose in the same place as the nasogastric tube. If the patients had no nasogastric tube the correct position of the $\mathrm{pH}$ probe was confirmed with an $x$-ray picture. The administration of the medication was entered into a diary.

The study protocol was approved by the Ethical Committee of Tampere University Hospital. Parental consent was obtained before $\mathrm{pH}$ monitoring procedures were carried out.

Statistical analysis was carried out using the analysis of variance. The equality of variances was tested using Levene's test, and BrownForsythe approximation was applied when necessary. Post-hoc comparisons were made using the Duncan multiple range test.

\section{Results}

The duration of monitoring of gastric $\mathrm{pH}$ varied from 30 to 70 hours (mean 44.3 hours). Five neonates received intravenous ranitidine $1.5 \mathrm{mg} / \mathrm{kg}$, six $1 \mathrm{mg} / \mathrm{kg}$, and five $0.5 \mathrm{mg} / \mathrm{kg}$ body weight as boluses (table 1). Ranitidine stopped the bleeding and no perforation occurred during treatment. No adverse side effects were seen.

According to the protocol, all infants had low intraluminal gastric $\mathrm{pH}$ before ranitidine started; mean $\mathrm{pH}$ at the starting point was 2.05 (SD 0.85). The highest values of gastric $\mathrm{pH}$ increased up to mean 7.53 (SD 0.62) with the doses given and in all 16 neonates $\mathrm{pH}$ increased beyond 4 . The higher the ranitidine dose, the faster gastric $\mathrm{pH}$ rose. The $1.5 \mathrm{mg} / \mathrm{kg}$ body weight dose increased the gastric $\mathrm{pH}$ within 0.9 hours (SD 0.65) and this was significantly more rapid than the dose of 0.5 $\mathrm{mg} / \mathrm{kg}$ body weight (mean 1.9 hours; SD 0.89 hours; $\mathrm{p}<0.034)$. In term infants gastric $\mathrm{pH}$ reached 5 significantly more quickly than in preterm infants (mean 0.9 hours; SD 0.46 vs mean 1.6 hours, SD $0.78 ; \mathrm{p}<0.005$ ) and the maximum gastric $\mathrm{pH}$ point was reached nearly twice as quickly (mean 2.64 hours, SD 0.98 vs mean 5.10 hours, SD 1.29 hours; $\mathrm{p}<0.001$ ).

Both gestational age and ranitidine dose had a significant impact on the maintenance of gastric $\mathrm{pH}$ over 4 (table 2). The highest dose kept the gastric $\mathrm{pH}$ above 4 for the longest period both in preterm and term neonates. The high gastric $\mathrm{pH}$ of preterm infants lasted for a significantly longer period than that of term 
infants. Although the bolus of $0.5 \mathrm{mg} / \mathrm{kg}$ was enough to increase the gastric $\mathrm{pH}$ in even term neonates, the dose had to be repeated every 2 to 5 hours to keep the gastric $\mathrm{pH}$ above 4 during a 24 hour period. Figure 1 shows the different gastric $\mathrm{pH}$ responses to ranitidine treatment in individual term and preterm infants.

After checking the individual gastric $\mathrm{pH}$ curves, and according to the results shown in table 2, the optimal ranitidine dose for term neonates is estimated to be $1.5 \mathrm{mg} / \mathrm{kg}$ body weight given intravenously three times a day. For preterm infants, $0.5 \mathrm{mg} / \mathrm{kg}$ body weight twice a day is sufficient.

\section{Discussion}

$\mathrm{H}_{2}$ blockers have been used for prophylactic as well as symptomatic treatment of stress induced gastric lesions in adults and children, including term and preterm neonates. ${ }^{2}{ }^{12} 13$ Ranitidine has been considered safe for the treatment of even critically ill neonates. ${ }^{10}$ The main mode of action of these $\mathrm{H}_{2}$ blockers is the increase in the gastric $\mathrm{pH}$ by decreasing the gastric acid output. Neonates can secrete gastric acid, ${ }^{514}$ but the gastric $\mathrm{pH}$ may also be alkaline. ${ }^{15}$ In our study the initial gastric $\mathrm{pH}$ was alkaline in six out of 22 $(27 \%)$. These infants might benefit from treatment other than an $\mathrm{H}_{2}$ blocker. We found that ranitidine treatment increased the gastric $\mathrm{pH}$ in every infant with initially low values. There was a clear difference between preterm and term infants in terms of the length of time intraluminal gastric $\mathrm{pH}$ was maintained above 4 .

Ranitidine, given either as boluses or as a continuous intravenous infusion, is equally effective. ${ }^{16}$ The bolus injection system was chosen to avoid the necessity for an extra intravenous infusion route, as ranitidine reacts easily with other drugs, leading to crystalloid formation. It was also easier to estimate the required individual dose of medication by using the bolus system. Breast feeding also increases intraluminal gastric $\mathrm{pH},{ }^{17}{ }^{18}$ but critically ill neonates mostly receive little or no oral feeds. Ranitidine boluses have the same effect on gastric $\mathrm{pH}$ as bolus breast feeding. Using a bolus dosage regimen, the resulting drop in gastric acidity acts as a barrier to the entry of micro-organisms into the intestine. ${ }^{18}$ The serum concentration of ranitidine did not help determine the optimal dose of the medication. ${ }^{8} 19$

The ranitidine dose used for children and neonates was derived from doses used for adults. The recommended dose of intravenous ranitidine was $1 \mathrm{mg}$ up to $5 \mathrm{mg} / \mathrm{kg}$ body weight per day. ${ }^{19}{ }^{20}$ However, it has been suggested that smaller children need smaller ranitidine doses. ${ }^{11}$ Our study, by measuring long term intraluminal gastric $\mathrm{pH}$, shows that preterm infants really need lower doses. As all the studied dose regimens were effective for preterm infants, the lowest dose was chosen. Adverse effects, such as bradycardia, have been linked with use of ranitidine. ${ }^{21}$ This, together with the preventive nature of the treatment, supported the selection of a clinically effective low dose$0.5 \mathrm{mg} / \mathrm{kg}$ body weight twice a day. By contrast, the dose of ranitidine needed for term infants was similar to that estimated earlier from adult studies and much higher than the dose for preterm infants. For term infants the dosing regimen requiring fewest doses per day to maintain 24 hour increased intraluminal gastric $\mathrm{pH}$ was $1.5 \mathrm{mg} / \mathrm{kg}$ body weight three times a day.

In conclusion, long term intraluminal gastric $\mathrm{pH}$ monitoring is an easy way to determine gastric acidity and was used to determine the required optimal dose of ranitidine to increase the gastric $\mathrm{pH}$ when treating critically ill preterm and term neonates. The results suggest that the required optimal dose of ranitidine for preterm infants is $0.5 \mathrm{mg} / \mathrm{kg} /$ body weight twice a day, and that for term infants, $1.5 \mathrm{mg} / \mathrm{kg}$ body weight three times a day.

1 Wilcox CM, Spenney JG. Stress ulcer prophylaxis in medical patients: Who, what, and how much? Am $\mathcal{F}$ Gastroenterol 1988;83:1199-204.

2 Mäki M, Ruuska T, Kuusela A-L, Karikoski-Leo R, Ikonen RS. High prevalence of asymptomatic esophageal and gastric lesions in preterm infants in intensive care. Crit Care Med 1993;21:1863-7.

3 Miller TA. Mechanisms of stress-related mucosal damage. Am $\mathcal{f}$ Med 1987;83(suppl 6A):8-11.

4 Kivilaakso E, Kiviluoto T, Mustonen H, Paimela H. Gastric mucosal acid-base balance. F Intern Med 1990;228(Suppl 1):63-8.

5 Hyman PE, Clarke DD, Everett SL, et al. Gastric acid secretory function in preterm infants. $\mathcal{F}$ Pediatr 1985;106:46771 .

6 Dimand RJ. Use of H2-receptor antagonists in children. Ann Pharmacother 1990;24:S42-6.

7 Sarna MS, Saili A, Dutta AK, Sharma D. Stress associated gastric bleeding in newborn - role of ranitidine. Indian Pediatr 1991;28:1305-8.

8 Fontana M, Tornaghi R, Petrillo M, Lora E, Porro GB, Principi N. Ranitidine treatment in newborn infants: Principi N. Ranitidine treatment in newborn infants: effects on gastric acidity and serum pro
atr Gastroenterol Nutr 1993;16:406-11.

9 Moore JG, Clemmer TP, Taylor S, Bishop AL, Maggio S. Twenty-four-hour intragastric $\mathrm{pH}$ patterns in ICU patients on ranitidine. Dig Dis Sci 1992;37:1802-9.

10 Wiest DB, O'Neal W, Reigart R, Brundage RC, Gillette PC, Yost RL. Pharmacokinetics of ranitidine in critically ill infants. Dev Pharmacol Ther 1989;12:7-12.

11 Kelly EJ, Chatfield SL, Brownlee KG, et al. The effect of intravenous ranitidine on the intragastric $\mathrm{pH}$ of preterm infants receiving dexamethasone. Arch Dis Child 1993;69:F37-9.

12 Shuman RB, Schuster DP, Zuckerman GR. Prophylactic therapy for stress ulcer bleeding: A reappraisal. Ann Intern Med 1987:106:562-7.

13 Kelly DA. Do H2 receptor antagonists have a therapeutic role in childhood? $f$ Pediatr Gastroenterol Nutr 1994;19:270-6.

14 Kelly EJ, Newell SJ, Brownlee KG, Primrose JN, Dear PRF. Gastric acid secretion in preterm infants. Early Hum Dev 1993;35:215-20.

15 Avery GB, Randolph JG, Weaver T. Gastric acidity in the first day of life. Pediatrics 1966;37:1005-7.

16 Ballesteros MA, Hogan DL, Koss MA, Isenberg JI. Bolus or Ballesteros MA, Hogan DL, Koss MA, Isenberg JI. Bolus or
intravenous infusion of ranitidine: Effects on gastric $\mathrm{pH}$ intravenous infusion of ranitidine: Effects on gastric

17 Sondheimer JM, Clark DA, Gervaise EP. Continuous gastric $\mathrm{pH}$ measurement in young and older preterm infants receiving formula and clear liquid feedings. F Pediatr Gastroenterol Nutr 1985;4:352-5.

18 Kelly EJ, Newell SJ. Gastric ontogeny: clinical implications. Arch Dis Child 1994;71:F136-41.

19 Newell S, Kelly EJ: Ranitidine in infants. Arch Dis Child 1993;69:544.

20 Fontana M, Massironi E, Rossi A, Vaglia P, Gancia GP, Tagliabue P, et al. Ranitidine pharmacokinetics in newborn infants. Arch Dis Child 1993;68:602-3.

21 Nahum E, Reish O, Naor N, Merlob P. Ranitidine-induced bradycardia in a neonate- a first report. Eur $\mathcal{F}$ Pediatr 1993;152:933-4. 